\title{
MENINGIOMA DA GOTEIRA OLFATIVA E CÂNCER DE MAMA
}

RELATO DE DOIS CASOS

PEDRO SAMPAIO * - CARLOS TELLES**-MAUD PARISE***

\begin{abstract}
RESUMO - Os autores relatam dois casos de meningioma da goteira olfativa em pacientes com câncer da mama. Referem três eventualidades que ocorrem em ambas as neoplasias: periodo etário predominante entre quinta e sexta décadas; presença em ambas de receptores de hormônios esteróides; e predominância do sexo feminino entre os meningiomas. Recomendam exame das mamas em mulheres com meningiomas e especulam sobre a possibilidade futura de tratamento hormonal coadjuvante para estes tumores. As imagens tomográficas feitas para controle pós-operatório ou quando aparecem sintomas neurológicos nem sempre diferenciam metástases de meningiomas, daí, às vezes, necessidace de verificação cirúrgica.
\end{abstract}

PALAVRAS-CHAVE: goteira olfativa, mama, meningioma, câncer, associação de tumores.

Olfactory groove meningioma and breast cancer: report of two cases

SUMMARY - Two cases of olfactory groove meningiomas are presented in patients with breast cancer. Predominance of breast cancer and meningiomas in the age decades of the forties and the fifties, presence of steroid hormones receptors in both and prevalence of meningiomas in women are referred as significant correlations. Examination of the breast of women with meningiomas is recommended. Tomographic images are sometimes atypical, and a surgical intervention may be necessary.

KEY WORDS: olfactory groove, breast, meningioma, cancer, tumor association.

A associação de meningioma e câncer de mama, mais que ocorrência fortuita, tem-se mostrado de inconteste significação estatistica. Schoenberg e col.12, em 1975, estudando a este propósito 5022 pacientes com tumores primitivos de diversas origens, demonstraram pela primeira vez esta relevante interrelação. De então para hoje, seguiram-se diversos trabalhos $1,2,4,8,13 \mathrm{com}$ escopo semelhante, estabelecendo-se de vez a constância deste achado. Na maioria dos casos publicados, os meningiomas foram diagnosticados após cirurgia do câncer da mama. Alguns porque apresentavam sintomas pertinentes, outros porque no controle pós-operatório periódico foram detectados pela tomografia computadorizada, como ocorreu com a paciente de nossa segunda observação. Casos houve em que o diagnóstico de câncer da mama se fez apenas após certo tempo decorrido da cirurgia de meningioma.

Alguns aspectos coincidentes mostram como os fatos mencionados se podem relacionar. Meningiomas e câncer de mama são mais numerosos na quinta e sexta década da vida 5,15 . Os meningiomas aparecem duas vezes mais em mulheres que em homens 3. Na gravidez ambos os tumores têm crescimento mais rápido 3,9 . Em ambos foi demonstrada a presença de receptores de hormônios esteróides 6,14. Neste passo, entretanto, há uma diferença não explicada à luz dos conhecimentos atuais. No câncer

Disciplina de Neurocirurgia, Universidade Estadual do Rio de Janeiro (UERJ): * Professor Titular; ** Professor Adjunto e Chefe da Clínica de Dor da Disciplina de Neurocirurgia; *** Médico Residente.

Dr. Pedro Sampaio - Servico de Neurocirurgia, Hospital Universitario Pedro Ernesto, UERJ Av. 28 de Setembro 77 - 20551 Rio de Jameiro $R J$ - Brasil. 
de mama encontram-se receptores de estrogênio e de progesterona em quantidades apreciáveis, enquanto nos meningiomas só os últimos aparecem em volume significante 10. Estudo mais aprofundado destes receptores pode, em futuro próximo, oferecer não somente explicações etiológicas quanto conduzir a terapêtica coadjuvante eficaz.

\section{OBSERVACOESS}

HST, paciente com 56 anos de idade, do sexo feminino, Reg. 2031, Clínica Santa Marta. Fm meados de 1976, começou a notar diminuiçăo progressiva da visão, o que a fez procurar um oftalmologista. Foi então observado, atrofia óptica à direita e escotoma central à esquerda. O exame neurológico, tirante a lesão oftalmológica foi inteiramente normal. Da história patológica constava cirurgia de câncer da mama realizada havia quatro anos. Ao tempo em que vimos a paciente não dispunhamos de tomografia computadorizada, por isso foi ela submetida apenas a angiografia cerebral (Fig. 1). Este exame mostrou volumoso meningioma da goteira olfativa, cuja cirurgia comprovou o diagnóstico.

MCF, paciente com 52 anos de idade, do sexo feminino, Reg. 52323, Hospital Samaritano. operada há um ano de câncer da mama, submeteu-se a controle clínico e radiológico de rotina, estando inteiramente assintomática. Foi surpreendida, com $o$ aparecimento de um meningioma da gotcira olfativa, à tomografia computadorizada (Fig. 2). O exame neurológico então realizado comprovou hiposmia bilateral e diminuição da acuidade visual com palidez papilar discreta à esquerda, achados não referidos espontaneamente pela paciente, Submeteu-se a craniotomia frontal bilateral, tendo-se feito extirpação completa do tumor e comprovado o diagnóstico.

\section{COMENTARIOS}

Nossa estatística de meningiomas intracranianos, operados no período compreendido entre 1967 e 1990, consta de 186 exemplares, sendo 17 situados na goteira olfativa. Dois casos, conforme as observações registradas, foram observados em pacientes que apresentavam câncer de mama.

É de interesse assinalar-se que os meningiomas da goteira olfativa, devido a sua topografia, podem desenvolver-se durante anos sem que o paciente se aperceba

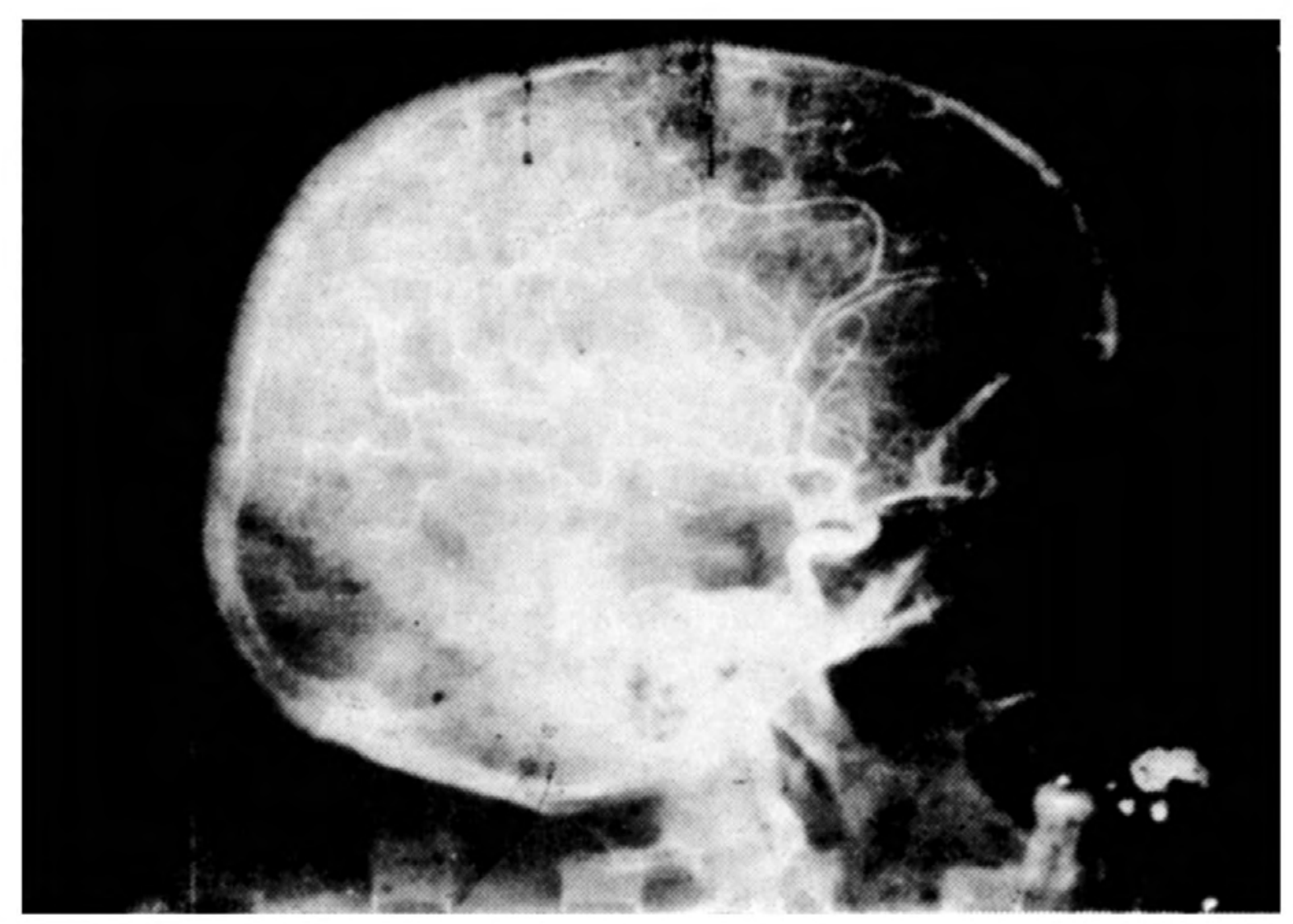

F'ig. 1. Angiografia cerebral em perfil mostnando elevação das artérias pericalosa e frontopolar, com concavidade para baixo, caracteristica de massa subfrontal. 


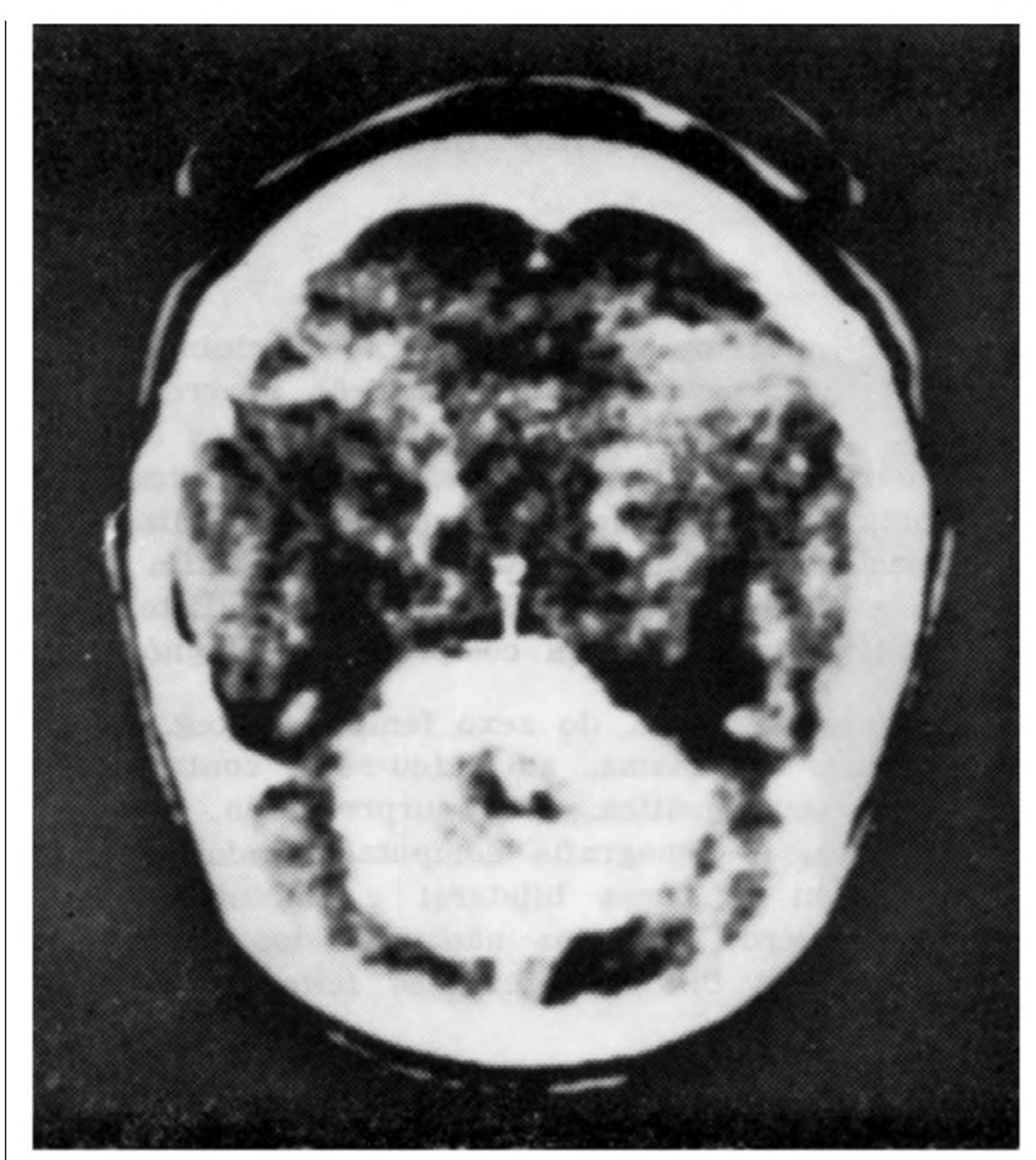

Fig. 2. Tomografia computadorizada ex:bindo extenso meningioma da goteira olfativa, com necrose central.

de qualquer anormalidade. O exame oftalmológico, entretanto, em $75 \%$ de nossos casos, mostrou anormalidade significativa.

Por constituirem os meningiomas desta região $10 \%$ aperas dos meningiomas intracranianos, a associação por nós encontrada é digna de ser assinalada. Encontramos na literatura revista apenas um caso desta associação 8 . Não sabemos como explicar a preferência por esta topografia em nossos casos, não se podendo afastar simples coincidência. $O$ mesmo não podemos dizer da associação de meningiomas em qualquer área cerebral e câncer de mama. Tal achado já se acha reiteradamente publicado e tem importância clínica e fisiopatológica. Este fato induz na prática a fazer-se rotineiramente exame acurado das mamas quando a paciente apresentar um meningioma e a incluir-se a tomografia computadorizada do crânio no estadiamento pré-operatório do câncer da mama ou, mesmo, no acompanhamento periódico das mulheres mastectomizadas.

Queremos também chamar atenção para os diagnósticos apressados de metástases cerebrais pela tomografia computadorizada 11. Tal como ocorre com as metástases, os meningiomas também podem ser múltiplos e apresentar áreas císticas. Em boa percentagem de casos a verificação cirúrgica é a única forma de certeza diagnóstica.

É pena deixar de operar-se um tumor benigno na suposição de tratar-se de metástase cerebral.

\section{REFERENCIAS}

1. Bachaud JM, Bonafe A, Bugat R. Cancer of the breast and meningioma: a non-fortuitious association. Presse Med 1984, 13:1273.

2. Bianchi C, Vassalo A, Di Bonito L, Gramusso V. Association cancer du sein-meningiome: à propos de deux observations. Sem Hop Paris 1980, 56:488-489.

3. Bickerstaff ER, Small JM, Guest IA. The relapsing course of certain meningiomas in relation to pregnancy and menstruation. J Neurol Neurosurg Psychiatry 1958, 21:89-91. 
4. Burns PE, Naresh J, Bain GO. Association of breast cancer with meningioma: report of two cases and review of the literature. Cancer 1986, 58:1537-1539.

5. Cushing H, Eisenhardt $H$. Meningiomas: Their Classlfication, Regional Behaviour, Life History and Surgical Results. Springfield: Charles C Thomas, 1938, p 73.

6. Goffin J. Estrogen and progesterone receptors in meningiomas: review article. Clin Neurol Neurosurg 1986, 88:169-175.

7. Jacobs DH, McFarlane MJ, Holmes FF. Female patients with meningioma of the sphenoid ridge and additional primary neoplasms of the breast and genital tract. Cancer 1987, 60:3080-3082.

8. Metha D, Khatib K, Patel S. Carcinoma of the breast and meningioma. Cancer 1983 , $51: 1937-1940$.

9. Michelsen JJ, New PFY. Brain tumor and pregnancy. J Neurol Neurosurg Psychiatry 1969, 32:305-307.

10. Plese JPP, Martins VR, Lopes MTP, Brentani MM. Arq Neuro-Psiquiat (São Paulo) 1985, $43: 365-371$.

11. Rubinstein AB. The association of carcinoma of the breast with meningioma. Surg Gynec Obtetr 1989, 169:334-336.

12. Schoenberg BS, Christine BW, Whisnant JP. Nervous system neoplasms and primary malignancies of other sites: the unique association between meningiomas and breast cancer. Neurology 1975, 25:705-712.

13. Smith FP, Slavik M, MacDonald JS. Association of breast cancer with meningiomas. Cancer 1978, 42:1992-1994.

14. Tilzer LL, Plapp, FV, Evans JP, Stone D, Alward K. Steroid receptor proteins in human meningiomas. Cancer 1982, 49:633-636.

15. Wara WM, Sheline JE, Neuman H. Radiation therapy of meningioma. Am J Roentgnol 1975, 123:453-458. 